\title{
Soot and Nanomaterials Synthesis in the Flame
}

\author{
Z. Mansurov \\ Institute of Combustion Problems, Almaty, Republic of Kazakhstan \\ Email: zmansurov@kaznu.kz
}

Received October 2013

\begin{abstract}
The general scheme of conversion of hydrocarbon fuels with new experimental data on the formation of fullerenes and graphenes taking into account the pressure effect is proposed for the fuel-rich flames. It is shown that the formation of fullerenes is important to the corresponding spatial orientation of PAH, possible at low pressures. The formation of hydrophobic soot surface on silicon and nickel substrates during combustion of propane-oxygen flame was studied. It is established that the hydrophobic properties are due to the presence of soot particles in the form nanobeads. The photovoltaic properties of solar cells coated by nickel oxide nanoparticles synthesized in counter flow propane-air flame. It is revealed that coated the surface of a silicon solar cell by nickel oxide nanoparticles results in the increase in solar cell efficiency by $3 \%$.
\end{abstract}

\section{KEYWORDS}

Soot; Nanomaterials; Hydrophobic; Nanoparticle

\section{Introduction}

The process of soot formation has been the object of numerous investigations for more than 100 years [1,2], and such investigations did not loose their significance to the present day. This is explained, first of all, by the fact that soot is an industrial product produced on a world scale in the amount of $10^{7}$ tons a year. The black (technological) carbon is used as a filler of elastometers (90\% of the technological carbon is used for this purpose, and 2/3 of it -in the production of tires) and has a wide application in printers. However, soot is a carcinogenic pollutant of the environment, formed as a result of the combustion of hydrocarbon fuels in power plants and engines. For example, diesel engines with direct fuel injection initially transform approximately $10 \%$ - $20 \%$ of the fuel introduced into the soot. Simultaneously with the soot formation, fullerenes and nanotubes are formed by the mechanism competing with the mechanism of soot formation. A knowledge of the conditions and mechanisms of formation of soot, fullerenes, and nanotubes in a flame allows one to change the combustion such that soot particles, fullerenes, or nanotubes are predominately formed.

At the present time a large number of experimental data on the processes of soot formation have been accumulated and different phenomenological models have been proposed [3,4]. However, the mechanism of soot formation is imperfectly understood yet. This is ex- plained by the fact that even in simple cases, such as the homogeneous pyrolysis of hydrocarbons, this process includes a large number of rapid simultaneous reactions leading to the formation of a new solid phase-soot particles (e.g., the time of transformation of methane with a molecular mass of 16 a.m.u into the soot with the molecular mass more than $10^{6}$ a.m.u makes $10^{-4}-10^{-2} \mathrm{~s}$ ).

Considerable interest of scientific and technical communities to study production processes, structure and properties of nanosized systems is caused by variety and uniqueness of their practical applications. The small size of structural components-typically up to $100 \mathrm{~nm}$ - determines the difference in the properties of nanomaterials from massive analogues. Flame is a self-sustaining system in which hydrocarbons can be precursors of carbon nanomaterials, and the heat released during combustion, is a parameter of the process control. It is known that $\mathrm{PAH}$ are nucleation centers of forming soot i.e. PAH can be converted into either soot or fullerenes. The formation of CNTs occurs in diffusion flames from the fuel side and is initiated by transition metals particles.

The $\mathrm{C}_{60}$ and $\mathrm{C}_{70}$ fullerene ions were detected in flames in 1987 and identified by the mass-spectrometry method [5]. Howard et al. [6] have obtained large amounts of $\mathrm{C}_{60}$ and $\mathrm{C}_{70}$ in laminar premixed soot forming flames of benzene and oxygen at low pressures. Unlike the evaporation of graphite, in the fullerenes formed in flames the ratio $\mathrm{C}_{70} / \mathrm{C}_{60}$ changes from 0.26 to 8.8 (in the case of 
evaporation of graphite, this ratio changes from 0.02 to $0.18)$.

The original results on development of carbon nanomaterials of different functional application which were obtained at the Institute of Combustion Problems.

\section{Formation of Soot and Synthesis of Fullerenes in Flame}

The formation of fullerenes occurs at low pressures, and corresponding space orientation which requires the account of steric factor is important here.

It should be noted, that formation of such elegant molecule of $\mathrm{C}_{60}$ requires the necessary space orientation of two molecules of $\mathrm{C}_{30}$. There are different formation models of fullerenes $\mathrm{C}_{60}$ one of which is carried out by zipper-mechanism.

Low pressures are the necessary conditions of such mechanism. With increasing of pressure, i.e., transition to the atmospheric and above, where triple collision take place and coagulation of PAH occurs, with formation of soot clusters. Howard has shown that the maximum of fullerene formation shifted to the right relative to the maximum of soot formation. At detailed examination by him the formation of fullerenes from benzene flame is shown that there is the second maximum at a distance of $70 \mathrm{~mm}$ from matrix of burner [6].

These data become the basis for development of alternative method for obtaining of fullerenes in the regime of hydrocarbons combustion.

A series of experiments on the study of the yield of fullerenes in a premixed benzene-argon-oxygen flame exposed to a longitudinal electric field under the conditions of a dark discharge, a corona discharge, and a glow discharge [4,7] at $\mathrm{C} / \mathrm{O}=1.0, \mathrm{P}=40$ torr, a benzene-flow rate $\mathrm{Q}_{1}=250 \mathrm{~cm}^{3} / \mathrm{min}$, an oxygen-flow rate $\mathrm{Q}_{2}=758$ $\mathrm{cm}^{3} / \mathrm{min}$, an argon-flow rate $\mathrm{Q}_{3}=101 \mathrm{~cm}^{3} / \mathrm{min}(10 \%$ of the combustion-mixture volume), $\mathrm{V}=18.4 \mathrm{~cm} / \mathrm{s}$.

It has been stated that the negative polarity of the upper electrode is more favorable for the fullerene formation as compared to the positive one. The investigations carried out under the conditions where the upper electrode was positioned directly above a flame have shown that, in this case, the yield of fullerenes increases. The influence of the type of an electrode and the height of its position above a flame on the formation of fullerenes was investigated for determining the conditions providing their maximum yield. Electrodes in the form of a needle and a ring were used. The investigations were carried out at a negative polarity of the upper electrode under the conditions where $\mathrm{U}_{\mathrm{H}}=7 \mathrm{kV}, \mathrm{H}=1-9 \mathrm{~cm}$ (with a step of $1 \mathrm{~cm})$. A glow discharge appeared independently of the type of an electrode at different heights of its disposition above the flame. In this case, the average temperature of the flame increased to $\mathrm{T}=1200^{\circ} \mathrm{C}$ (without a field, this temperature was equal to $\mathrm{T}=950^{\circ} \mathrm{C}$ ).

Thus, it has been stated that the yield of fullerenes increases under the action of a glow discharge in the case where an electrode (a needle or a ring) is positioned directly above flame and that a maximum yield of fullerenes is attained with the use of a ring electrode placed above the central region of the flame front. The maximum yield of the fullerene $\mathrm{C}_{60}$ was $\beta=15 \%$ of the soot formed.

\section{Formation of Carbon Nanotubes in Flames}

The most promising way to produce carbon nanotubes, according to Merchan-Merchan et al. [8], is the flame method. In the synthesis of carbon nanoparticles using flames, part of the fuel is consumed in heating of the mixture, and part is used as a reactant, which makes this method more cost-effective than methods based on the use of electricity, pyrolysis of hydrocarbons or arc evaporation of graphite.

The results of the study of a flat diffusion propaneoxygen flame stabilized on an opposed-jet burner at atmospheric pressure are presented in [7]. Two opposed flows formed the flat flame. The flame was surrounded by an external nitrogen flow supplied from the burner matrices. A solution of catalyst $\left[\mathrm{Fe}(\mathrm{CO})_{5}\right.$ or an alcohol solution of nickel nitrate] was sprayed by an ultrasonic nebulizer and delivered through a metal nozzle into the flame from the side of the fuel.

The resulting products were deposited on the walls of the reactor and collected in traps with liquid nitrogen. The temperature in the reactor was measured by a thermocouple, and in the flame by an Iron Ultrimax pyrometer.

It is evident from Figure 1 that the samples contain soot agglomerates, among which metal particles are encountered. It was found that under certain experimental conditions, well-ordered bundles of carbon nanotubes 20 - $30 \mathrm{~nm}$ in diameter formed.

\section{Formation of Hydrophobic Soot in Hydrocarbon Flames}

Low surface-energy materials like amorphous carbon (a-C) films are frequently used to modify surfaces in order to control their wettability. The nanobeads are morphologically similar to the carbon nanopearls synthesized by Levesque and co-workers [9] through acetylene dissociation at $700^{\circ} \mathrm{C}$ on nickel catalyst nanoclusters. Puri et $a l$. have determined new ways of the synthesis of carbon nanotubes in the fuel-rich diffusion flames, exposed to an electric field during 2 - $10 \mathrm{~min}$, on superhydrophobic surfaces representing nanodimensional round amorphous 

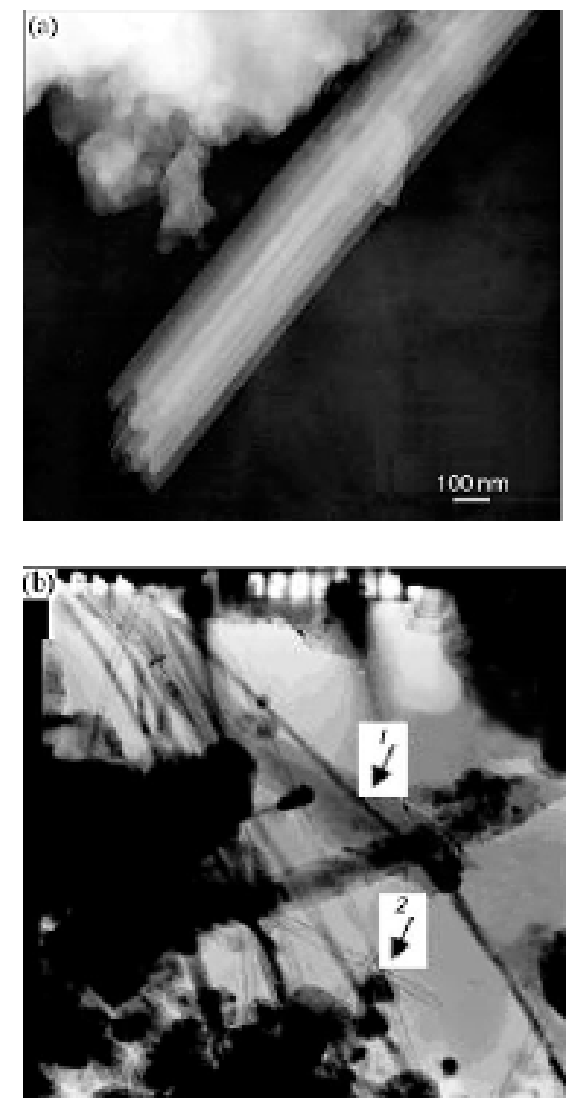

Figure 1. Electron micrographs of samples: (1) carbon nanotube; (2) $\mathrm{Ni}$ in a carbon shell.

carbon particles deposited on a silicon substrate [10].

The formation of hydrophobic soot surface on silicon and nickel substrates during combustion of propaneoxygen flame was studied [11]. It is stated that the hydrophobic properties are due to the presence of soot particles in the form nanobeads. The schematic diagram of the synthesis process is presented in Figure 2 and Figure 3 shows water droplets on superhydrophobic soot.

Studies have shown that carbon deposits on the plates different in the morphological structure of deposited particles in different zones. In the central and middle zone long chains of individuals formed in the form nanobeads 15 - $30 \mathrm{~nm}$ without applying an electric field, and 40 - 50 $\mathrm{nm}$ with an electric field. In the outer zone, regardless of the conditions of combustion, there are coagulated aggregates of soot particles with sizes $30-50 \mathrm{~nm}$.

The results for the exploration of the soot formation of hydrophobic surfaces on silicon substrates and nickel during combustion of propane oxygen flame are listed. The distance from the burner matrix and the substrate was varied, the exposure time and the influence of the electric field of different polarity and voltage. It is shown that at the exposure of more than 4 minutes the soot with hydrophobic properties is formed and a division of the soot surface area occurs. The application of an electric

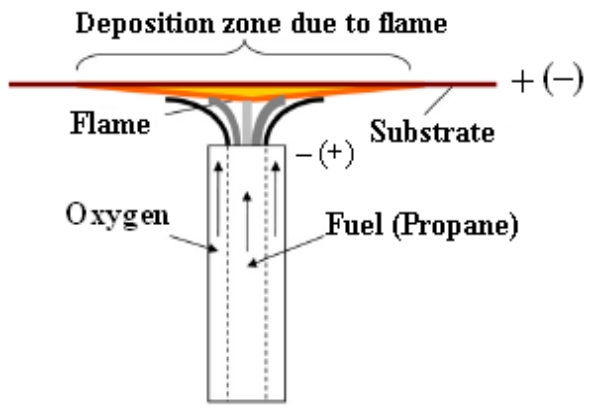

Figure 2. Schematic diagram of the synthesis process.

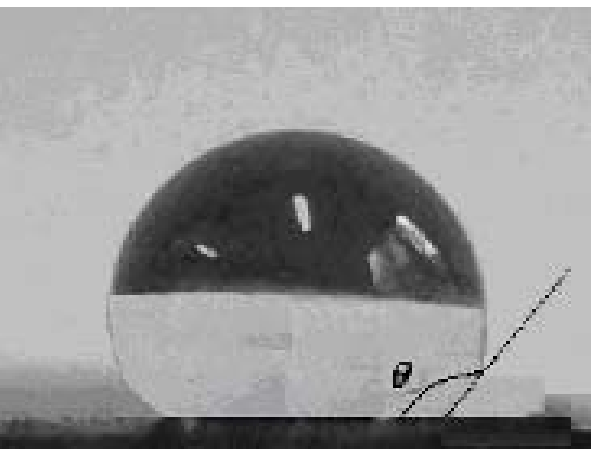

Figure 3. Water droplets on superhydrophobic soot.

field narrows the soot deposition on the substrate and in diameter of $2.5-3 \mathrm{~cm}$ from the centre; the soot super hydrophobic surface with a wetting angle of more than $170^{\circ}$ is formed.

\section{Formation of a Layered Graphene in the Flames}

The study of the formation of layered graphene films was carried out in the propane-oxygen flame under the following conditions: flow rate of propane- $-219.1 \mathrm{~cm}^{3} / \mathrm{min}$, the flow of oxygen- $381.2 \mathrm{~cm}^{3} / \mathrm{min}$, corresponding to the ratio of $\mathrm{C} / \mathrm{O}=0.86$.

The studies were carried out both with the addition of argon in benzene-oxygen mixture in an amount of 300 $650 \mathrm{~cm}^{3} / \mathrm{min}$ and without argon. As catalytic substrates used plates made of copper and nickel, are placed in the fire.

Varied range of residence time of the substrate in the flame: 5, 10, 20, 30, 40, 60 seconds, 5 and 10 minutes, the angle varied substrate relative to the vertical axis of the flame: $\alpha=0^{\circ}, 30^{\circ}, 45^{\circ}, 60^{\circ}, 85^{\circ}$. Flame temperature in the experiments was in the range $900^{\circ}-950^{\circ}$. Formed on the substrate samples were examined for particulate structures Raman spectrometer NTEGRA Spectra.

It was found that a substrate of nickel is more preferred for the synthesis of graphene films. A copper catalyst substrate is an intensive formation of the amorphous structure of carbon black and copper oxides. Further studies were conducted on a nickel substrate. 
Figure 4 shows the Raman spectrum of the two layers of graphene, when placed in a flame of nickel substrate at an angle of 30 degrees to the vertical axis of the flame yielded two layers (IG/I2D = 1,1), Raman spectrum is shown in Figure 4(a). The further increase in the angle of inclination of the substrate relative to the vertical axis of the flame (over $30^{\circ}$ ) leads to the increase in the minimum number of graphene layers formed on a substrate from 5 to 10 (IG/I2D = 1,7 - 2,4), Figure 4(b).

On the basis of the data on synthesis of fullerenes, carbon nanotubes, superhydrophobic soot and graphene in the flame it is possible to modify the general scheme proposed by H. Bockhorn [12] for rich fuel flames, namely

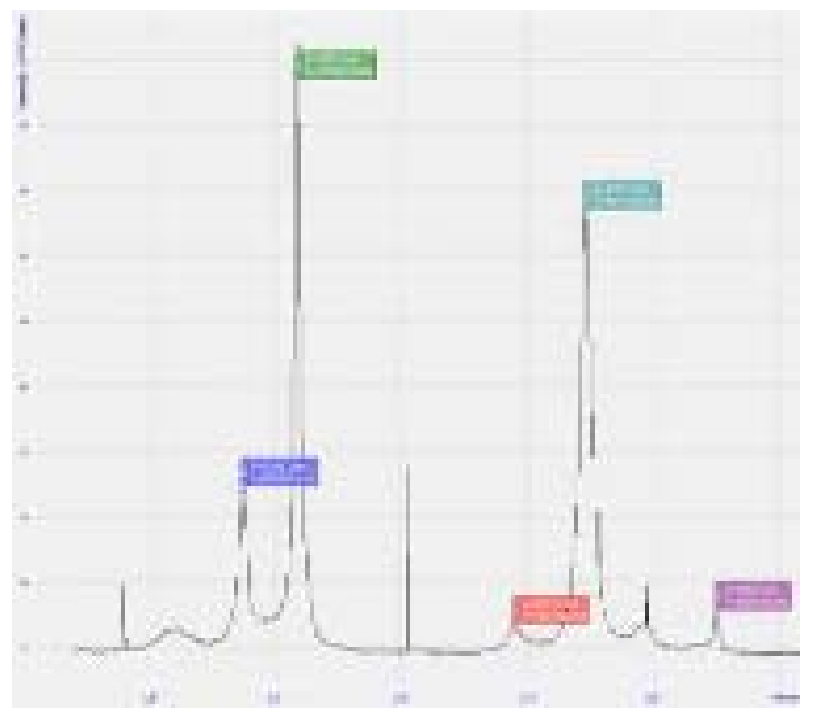

(a)

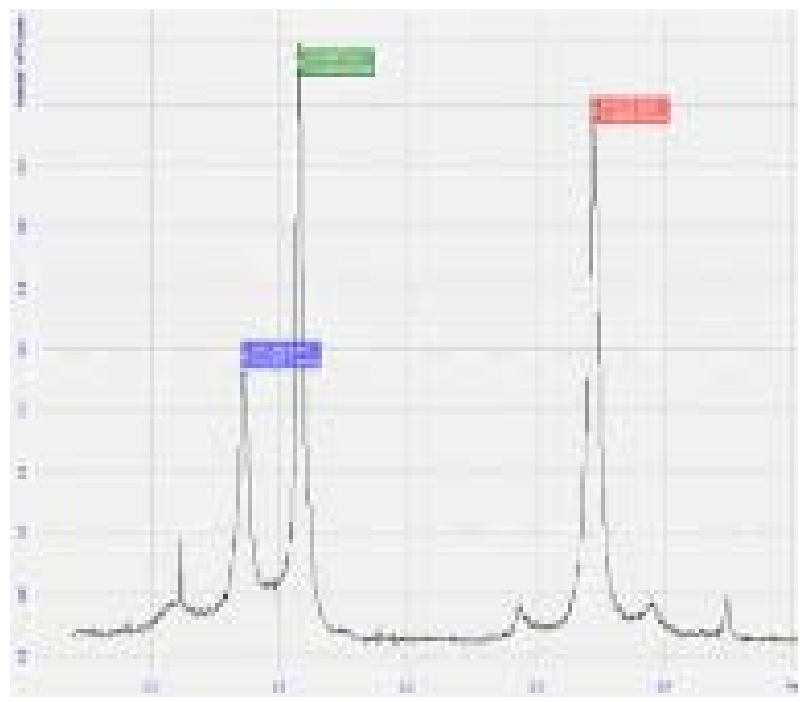

(b)

Figure 4. Raman spectra of graphene layers synthesized on nickel substrate in propane-oxygen-argon flame $(\mathrm{C} / \mathrm{O}=\mathbf{0 . 8 6}$; $\left.\mathrm{t}=917^{\circ} \mathrm{C} ; \tau=5 \mathrm{~min}\right)$; (a) two layers $\left(\alpha=30^{\circ}, \mathrm{IG} / \mathrm{I} 2 \mathrm{D}=1,1\right)$; (b) five layers $\left(\alpha=45^{\circ}\right.$, IG/I2D $\left.=1,7\right)$. to make a pressure-coordinate, which allows the formation of fullerenes at low pressures, and soot at high pressures. In addition the scheme was completed by graphene formation as an intermediate product stage of graphene formation (Figure 5).

\section{Increase of the Power of Solar Elements Using Nickel Oxide Nanoparticles Synthesized in Flame}

The main advantage of synthesis of nanoparticles in hydrocarbon flames is that average time of the full conversion of fuel in a narrow zone of flame front is a few milliseconds that provide nearly immediate formation of expected product. Catalysts which are necessary for the growth of nanoparticles of metals or their oxides can be introduced. Different types and methods of introducing catalysts into reaction flame zone allow influencing the properties and sizes of nanoparticles being obtained [13].

This work presents the results of the investigations on synthesis of nickel oxide nanoparticles in propane-oxygen counter-flow flame [14]. The generated nanoparticles are subsequently used to increase the efficiency of light conversion in the solar cells.

The burner is positioned inside a hollow stainless steel cylinder with the diameter of $150 \mathrm{~mm}$ and height of 82 mm. Two nozzles are installed on the axis of this cylinder opposite to each other. The nozzles are composed of two cylinders with one cylinder inserted into another. Oxidizer and fuel are supplied through the internal cylinders from the opposite sides. In this study, propane was used as a fuel and oxygen was used as an oxidizer. A

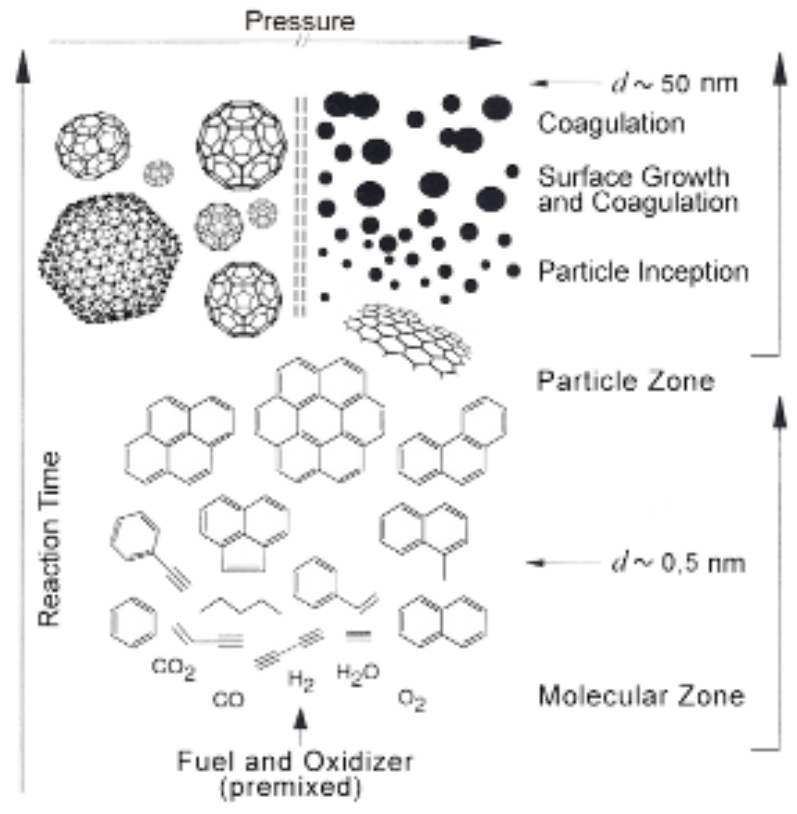

Figure 5. Modified scheme for soot, fullerenes and graphene formation process in flames. 
diameter of a visible flame front was 30 - 35 mm.

Nichrome wire with the diameter of $0.3 \mathrm{~mm}$ was used as a substrate for the growth of nickel oxide nanoparticles. X-ray fluorescent analysis of Nichrome wire shows the following composition: $\mathrm{Ni}-60.27 \%, \mathrm{Fe}-25.26 \%$, $\mathrm{Cr}-14.45 \%$ and $\mathrm{Ti}-0.0174 \%$. Before nanoparticle synthesis, Nicrome wire was pretreated for 20 minutes with $25 \%$ solution of nitric acid.

Figure 6 shows scanning electron microscope (SEM) images of Nichrome wire treated in oxygen zone of diffusion counter flow propane-oxygen flame for the time interval of 2 minutes.

The results of SEM studies show that the treatment of nicrome wire with flame for 2 minutes leads to the formation of nickel oxide nanoparticles on its surface with an average size of $300 \mathrm{~nm}$. High temperature and active radicals formed in propane-oxygen flame interact with nickel surface promoting the growth of nickel nanoparticles. After coating of nickel oxide nanoparticle were on the surface of solar cell on atomic power microscope. The resulting image (Figure 7) shows that the size of metal oxide nanoparticles on the surface of a solar cell depends on the residence time in the flame.

Silicon solar cells with an active region of $1 \mathrm{~cm}^{2}$ were used in this study. The solar elements being investigated were made of monocrystalline silicon alloyed with boron of p-type conductivity with specific resistance of 10 $\mathrm{Ohm} \cdot \mathrm{cm}$ and specific crystallographic orientation (100).

Silicon plates with the thickness of $300 \mu \mathrm{m}$ were smoothly-polished on both sides. Frontal n-layer was formed by a thermal diffusion of $\mathrm{POCl}_{3}$ at the temperature of $900^{\circ} \mathrm{C}$ for 20 minutes in inert medium. This

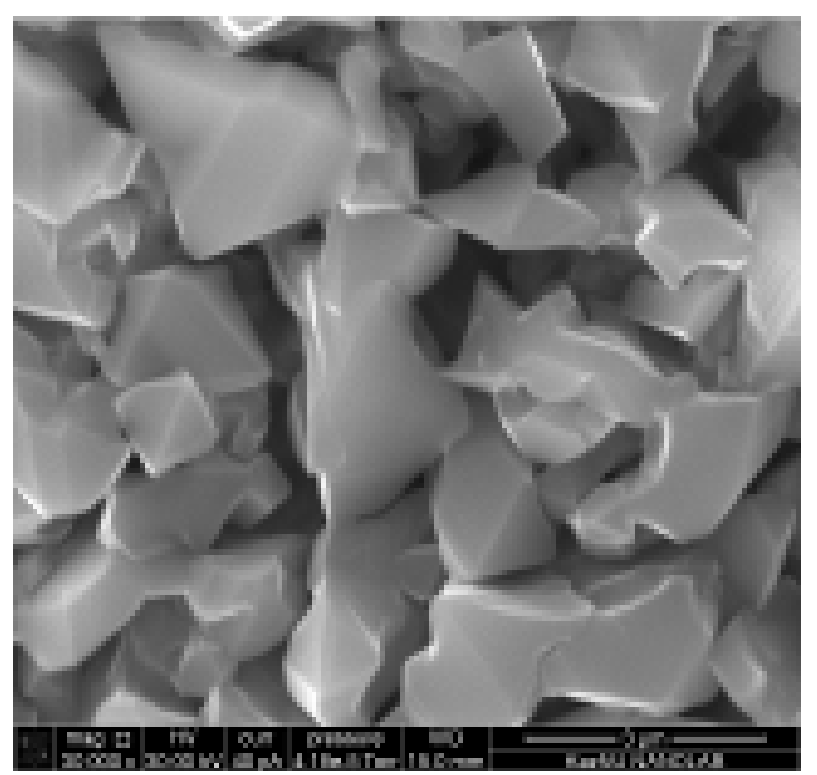

Figure 6. SEM images of a nichrome wire treated in the oxygen zone of the diffusion counter flow propane-oxygen flame.

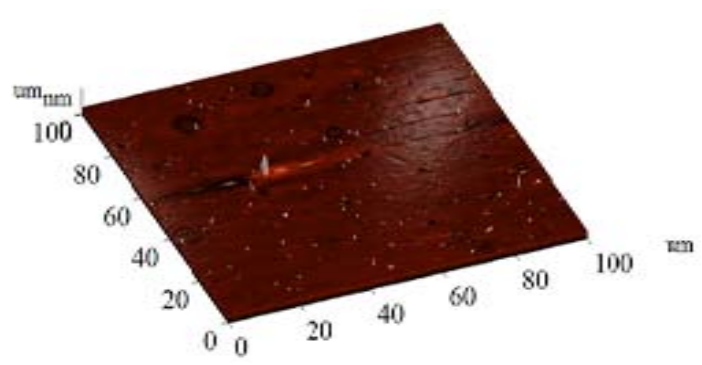

(a)

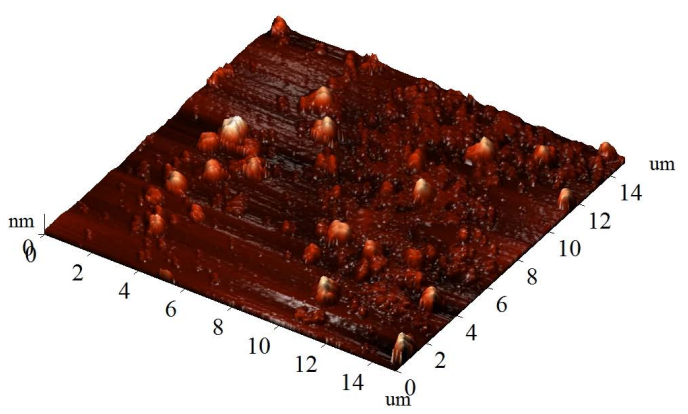

(b)

Figure 7. Micrograph of nickel oxide nanoparticles on the surface of the solar cell, $5 \mathrm{sec}$ (a) $2 \mathrm{~min}$ (b).

resulted in the formation of p-n transition with the thickness of $\sim 0.3 \mu \mathrm{m}$. Back contact was formed by spraying metallic aluminum in high vacuum with subsequent annealing at $700^{\circ} \mathrm{C}$. Front side Ti-Ag contacts were applied using photolithography. In-Ga contact was soldered directly to n-layer. The surface of the solar cell of such a construction was covered with nickel oxide nanoparticles.

To obtain uniform coating based on nanoparticles on the surface of the solar cell, suspension of nanoparticles in ethanol was preliminary created using an ultrasonic bath. Up to $0.1 \mathrm{ml}$ of suspension was necessary to coat one solar element. Prior to coating, the measurements of a short-circuit current and an open-circuit voltage of noncoated solar element were carried out. Without changing the conditions of the experiment short-circuits current and open-circuit voltage were measured after application of the coating.

The measurement unit consisted of the chamber covered with lightproof tissue from the outside to protect it from mechanical dust and external sources of radiation. Halogen lamp which stably radiated light similar to solar spectrum was used as a source of light. Inside the chamber there was a special support for fixing the solar cell. The chamber allowed reproducible measurements with a great accuracy irrespective of the substitution of a sample being investigated. The measurements for each sample were carried out with the time interval of 30 minutes for 3 hours. The values of current and voltage were registered using multimeter (with the accuracy of $\pm 0.5 \%$ ). 
Power output of uncoated vs. coated solar cell with high concentration of nickel oxide/methanol suspension. Bars indicate a 95\% confidence interval for measured values (Figure 8).

The wavelength dependent light transmission of the coating applied to the surface of the solar element is of a great importance for its effective work. The spectra of the transmission of the coating based on nickel oxide nanoparticles to the surface of quartz substrate with the concentration of $8 \times 10^{4}$ particle/ $\mathrm{cm}^{2}$ were recorded in a wavelength range from 400 to $1100 \mathrm{~nm}$. The analysis shows that in a short-wave region a slight decrease is observed, because of light absorption in nanostructures whereas in visible and long-wave regions transmission coefficient reaches $93 \%$.

Open-circuit voltage increased to $4 \%-7 \%$, the shortcircuit current increased to $20 \%-28 \%$, efficiency of the solar cells increased by $2 \%$ to $3 \%$, at a fill factor of the element being equal to 0.75 . The absence of other factors which may cause the increase of the output power of the solar cells means that original cause is the application of nanoparticles.

We would like to note uniqueness of using the counter flow of the burner to the opposing jets for the synthesis of nanomaterials, which was created by Potter [15] and Weinberg [16] to study the structure of the flame front.

Diffusion burner on the counter flow can be effectively used for the production of carbon nanotubes in the synthesis of the fuel, as well as for the introduction of metal oxide nichrome wire into the zone of oxygen supply.

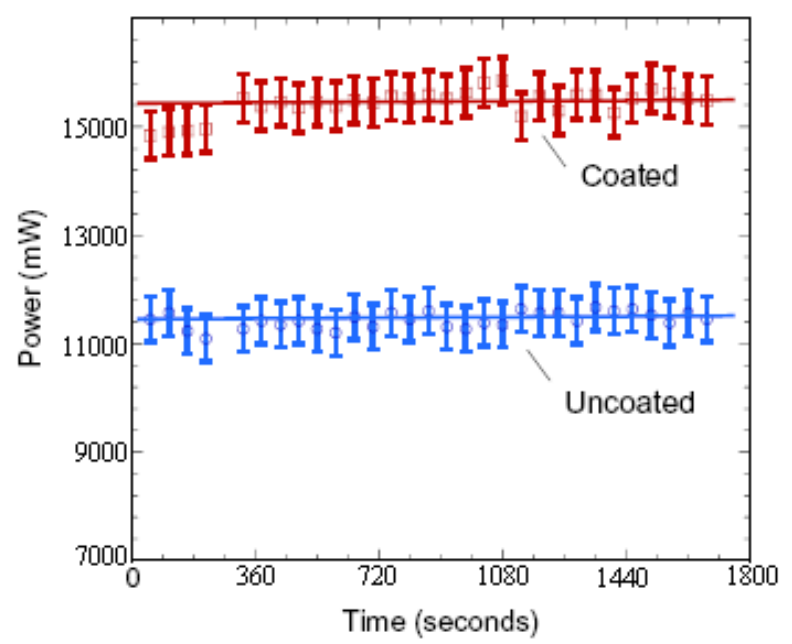

Figure 8. Power output of uncoated vs. coated solar cell with high concentration of nickel oxide/methanol suspension.

\section{REFERENCES}

[1] J. J. Thomson, "LVIII. On the Masses of the Ions in Gases at Low Pressures,” Philosophical Magazine Series 5, Vol. 48, No. 295, 1899, pp. 547-567. http://dx.doi.org/10.1080/14786449908621447

[2] H. A. Wilson, "The Electrical Properties of Flames and Incandescent Solids,” University Press, London, 1912.

[3] K. H. Homann and H. G. Wagner, "Some Aspect of Soot Formation,” In: J. Ray Bawen, Ed., Dynamics of Exothermicity (Combust. Sc. Techol. Book Series, Vol. 2), Carbon and Breach Publishers, 1996, pp. 151-184.

[4] Z. A. Mansurov, "Soot Formation in Combustion Processes (Review)," Combustion, Explosion and Shock Waves, Vol. 41, No. 6, 2005, pp. 727-744. http://dx.doi.org/10.1007/s10573-005-0083-2

[5] P. Gerhardt, S. Loffler and K. H. Homann, Proc. $22^{\text {nd }}$ Int. Symp. Combust., The Combustion Inst., Pittsburgh, 1988, pp. 395-401.

[6] J. B. Howard, A. L. Lafleur, et al., Carbon, Vol. 30, 1992, pp. 1183-1201. http://dx.doi.org/10.1016/0008-6223(92)90061-Z

[7] Z. A. Mansurov, Combustion, Expolsion and Shock Waves, Vol. 48, No. 5, 2012, pp. 561-569.

[8] W. Merchan-Merchan, A. V. Saveliev and L. A. Kennedy, "Flame Nanotube Synthesis in Moderate Electric Fields: From Alignment and Growth Rate Effects to Structural Variations and Branching Phenomena," Carbon, Vol. 44, 2006, pp. 3308-3314. http://dx.doi.org/10.1016/j.carbon.2006.06.025

[9] A. Levesque, V. T. Binh, et al., Thin Solid Films, Vol. 464-465, 2004, pp. 308-314. http://dx.doi.org/10.1016/j.tsf.2004.06.012

[10] S. Naha, S. Sen and I. K. Puri, Carbon, Vol. 45, 2007, pp. 1696-1716. http://dx.doi.org/10.1016/j.carbon.2007.04.018

[11] Z. A. Mansurov, Advanced Materialials Research, Vol. 486, 2012, pp. 134-139

[12] H. Bockhorn, "Soot Formation in Combustion," Springer, Berlin/Heidelberg, 1994, p. 4. http://dx.doi.org/10.1007/978-3-642-85167-4

[13] I. A. Kuznetsov, M. J. Greenfield, Y. U. Mehta, W. Merchan-Merchan, G. Salkar and A. V. Saveliev, Applied Energy, Vol. 88, 2011, pp. 4218-4221. http://dx.doi.org/10.1016/j.apenergy.2011.04.033

[14] Z. A. Mansurov M. Auyelkhankyzy, B. T. Lesbayev, et al. Advanced Materials Research, Vol. 486, 2012, pp 140144.

[15] A. E. Potter, S. Heimel and J. N. Butler, 8th Symposium (Int) on Combustion, 1962, pp. 1027-1034.

[16] T. P. Pandya and F. J. Weinberg, 9th Symposium (Int) on Combustion, 1963, pp. 587-596. 